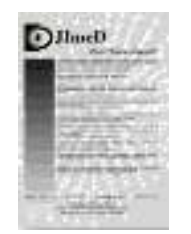

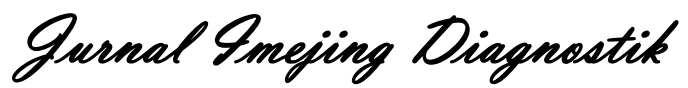

e-ISSN 2621-7457, p-ISSN 2356-301X

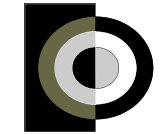

http://ejournal.poltekkessmg.ac.id/ojs/index.php/jimed/index

\title{
Perbedaan Kualitas Citra MRI Lumbal sekuen T1WI TSE Potongan Sagital dengan dan tanpa Penggunaan Sensitivity Encoding (SENSE) pada Kasus Hernia Nucleus Pulposus
}

\author{
Rini Indrati ${ }^{1)}$, Iin Saputri Sahlan ${ }^{2)}$, Bambang Satoto ${ }^{3)}$, Siti Daryati ${ }^{4)}$ \\ 1, 2,4) Jurusan Teknik Radiodiagnostik dan Radioterapi, Poltekkes Kemenkes Semarang, Indonesia \\ ${ }^{3)}$ RS Dr. Kariadi Semarang, Indonesia \\ Corresponding author: Rini Indrati \\ Email: riniindrati@poltekkes-smg.ac.id
}

Received: January $30^{\text {th }}, 2020$; Revised: January $31^{\text {th }}, 2020$; Accepted: January $31^{\text {th }}, 2020$

\begin{abstract}
Background: Parallel imaging is a time-reduction technique that uses phased-array coils. Phased array coils measure and process signals from a piece, then combine pieces to form an image of a larger area of anatomy. Commonly used imaging parallel technique is one of them is sensitivity encoding or SENSE. This research is the difference of image quality MRI Lumbal sequence T1WI TSE of sagittal pieces with and without the use of SENSE in the case of hernia nucleus pulposus (HNP). The aim of this research is to know the difference between SNR, anatomy information and better image quality and anatomical information. MRI Lumbal sequence T1WI TSE sagittal pieces with and without the SENSE in HNP.

Methods: The type of this research is quantitative with an experimental approach, The research was conducted in RS dr. Saiful Anwar Malang. The research was taken from Lumbal MRI examination in 9 patients with predetermined exclusion and inclusion criteria of T1WI TSE sectional pieces with and without the use of SENSE in HNP. Image assessment was done by two radiologists. Analysis of data used paired T-test and Wilcoxon test with alpha 5\%.

Results: The results showed that there was a difference in image quality of MRI Lumbal T1WI TSE sequence of sagittal pieces with and without the use of SENSE in HNP with p-value $=0.001$, and anatomic information with $\mathrm{p}$-value $=0.001$. Sensitivity encoding resulted in better image quality and anatomical information, with mean values at SNR 181,4333, and rank information anatomy 11,00.

Conclusion: There is a difference in SNR and anatomical information between the use of SENSE and without the use of SENSE on sagittal lumbar MRI. The use of SENSE is capable of producing quality MRI imagery (SNR) and Anatomical Information on lumbar MRI lumbar sequences of sagittal slices.
\end{abstract}

Keywords: T1WI TSE; Sensitivity encoding; MRI Lumbal; HNP

\section{Pendahuluan}

Reduksi scan time dalam parallel imaging pemeriksaan Magnetik Resonance Imaging (MRI) memiliki beberapa manfaat. Pertama, sangat berguna untuk sekuen yang tergantung pada waktu scanning pendek seperti single breath hold. Kedua, waktu pemeriksaan keseluruhan dapat dikurangi, terutama pada pasien dengan keluhan nyeri yang hebat pada posisi tertentu seperti nyeri saat berbaring, pada pasien anak-anak atau pada kasuskasus emergensi (Forshult, 2007; Yasuyuki, 2002). Salah satu kelainan pada lumbal yang sering terjadi yaitu hernia nukleus pulposus (HNP) yang dapat menyebabkan nyeri pada bagian tulang belakang yang dapat berimbas pada nyeri pada bagian paha, betis dan kaki bahkan dapat menyebabkan kelainan bentuk tulang belakang. Pada pemeriksaan kasus HNP kadang pasien merasa yang kurang nyaman karena lamanya pemeriksaan sehingga dibutuhkan teknik untuk mengurangi waktu pemeriksaan (Fitriyani, 2017). Salah satu cara mempercepat akuisisi data MRI adalah dengan mengurangi waktu pemeriksaan yaitu dengan menggunakan teknik akuisisi pararel atau teknik paralel imaging (Deshmane, 2012; Filippi, 2012). 
Paralel imaging merupakan teknik pengurangan waktu yang menggunakan phased array coil. Phased array coil mengukur dan memproses sinyal dari sebuah potongan, kemudian menggabungkan potongan untuk membentuk gambar area yang lebih besar dari anatomi. Teknik akuisisi paralel memperoleh bagian dari K-space dengan susunan kumparan penerima dari setiap koil elemen, kemudian menggabungkannya untuk membentuk gambar akhir. Waktu akuisisi menjadi berkurang karena berkurangnya jumlah baris yang diperoleh untuk setiap elemen (Glockner, 2005).

Teknik paralel imaging yang biasa digunakan yaitu salah satunya adalah sensitivity encoding atau SENSE. Parameter SENSE yang biasa digunakan disetiap merk MRI sesuai vendor yaitu philips (SENSE), Siemens (Msense), Toshiba (SPEEDER), Hitachi (RAPID), GE (ASSET). Sensitivity encoding merupakan algoritma Parallel Magnetic Resonance Imaging (MRI) yang memanfaatkan sensitivitas koil receiver menggunakan citra yang dibentuk oleh koil phased array (Glockner, 2005; Elster, 2015)

Studi pendahuluan yang dilakukan di beberapa Rumah Sakit pada pemeriksaan MRI lumbal dengan kasus hernia nucleus pulposus (HNP) tidak selalu mengaktifkan Sensitifity Encoding (SENSE). Penelitian dimaksudkan untuk mengetahui pengaruh pengaktifan SENSE terhadap kualitas citra MRI ditinjau dari kualitas citra SNR yang dihasilkan dan informasi anatomi yang dihasilkan.

\section{Metode}

Jenis penelitian ini adalah kuantitatif dengan pendekatan eksperimental one shot case study. Sebanyak sembilan orang pasien terlibat dalam penelitian ini sebagai sampel. Sampel adalah pasien yang melakukan pemeriksaan MRI lumbal dengan dua perlakuan pada satu orang sampel yaitu dengan memberikan sekuen T1WI TSE lumbal potongan sagital dengan dan tanpa penggunaan Sensitivity Encoding.

Data berupa Nilai Signal to Noise Ratio (SNR) diambil dengan melakukan pengukuran menggunakan automatic software yang ada pada pesawat MRI. Data berupa kejelasan informasi anatomi dilakukan penilaian oleh dokter spesialis radiologi meliputi kejelasan korpus vertebra lumbalis, discus intervertebral lumbalis, spinal cord dan Cerebro Spinal Fluid (CSF) menggunakan Cheklist dengan skala ordinal (Mueller, 2003; Mueller, 2007).
Data berupa kualitas citra (SNR) MRI lumbal sekuen T1WI TSE potongan sagital pada kasus Hernia Nucleus Pulposus (HNP) dianalisis dengan pauret $\mathrm{t}$ test sedangkan data berupa informasi anatomi dianalisis dengan menggunakan wilcoxon test pada tingkat kesalahan 5\% (Notoadmojo, 2002).

\section{Hasil dan Pembahasan}

\section{Analisis Diskriptif}

Penelitian dilakukan pada sembilan pasien berjenis kelamin laki-laki dan perempuan dengan rentang usia 40-80 tahun dan memiliki kelainan pada daerah lumbalis. Karakteristik sampel berdasarkan jenis kelamin seperti pada tabel 1.

Tabel 1. Karakteristik Sampel Berdasarkan Jenis Kelamin

\begin{tabular}{lcc}
\hline \multicolumn{1}{c}{ Jenis Kelamin } & Jumlah & Persentase \\
\hline Laki-laki & 3 & $33 \%$ \\
Perempuan & 6 & $67 \%$ \\
\hline Total & 9 & $100 \%$ \\
\hline
\end{tabular}

Pada penelitian ini menggunakan sembilan sampel pasien MRI Lumbal dengan kasus HNP yang terdiri dari 3 (33\%) sampel laki-laki dan 6 (67\%) sampel perempuan. Karakteristik sampel berdasarkan umur seperti ditampilkan pada tabel 2.

Tabel 2. Karakteristik Sampel Berdasarkan Umur

\begin{tabular}{ccc}
\hline Umur & Jumlah & Persentase \\
\hline $40-50$ & 3 & $33 \%$ \\
$51-60$ & 4 & $44 \%$ \\
$61-70$ & 1 & $11 \%$ \\
$71-80$ & 1 & $11 \%$ \\
\hline Total & 9 & $100 \%$ \\
\hline
\end{tabular}

Umur sampel penelitian antara rentang 40-50 tahun sebanyak 3 (33\%) orang, pasien berumur 51-60 tahun sebanyak 4 (44\%) orang, dan pasien berumur 61-7- dan 71-80 masing-masing 1 (11\%) orang.

Citra yang dihasilkan dari pemeriksaan MRI lumbal sekuen T1WI TSE potongan sagital pada kasus Hernia Nucleus Pulposus (HNP) antara penggunaan SENSE dan tanpa penggunaan SENSE seperti disajikan pada Gambar 1. Nomor yang ditunjuk adalah anatomi Citra MRI Lumbal potongan sagital yang dinilai kejelasannya oleh dokter spesialis radiologi meliputi Corpus vertebrae lumbalis, Discus intervertebrae lumbalis, Spinal cord dan Cerebro spinal fluid (CSF) 


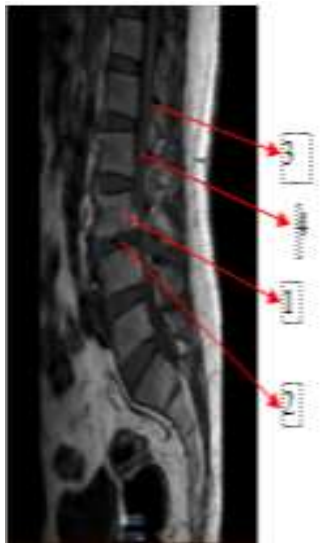

a. SENSE ON

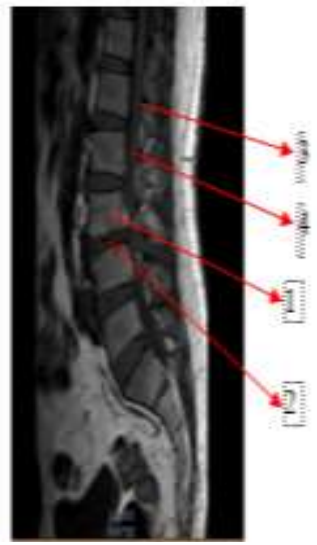

b. SENSE OFF
Gambar 1. Hasil citra MRI Lumbal pada kasus HNP pada variasi penggunaan SENSE

Keterangan Gambar :

1. Corpus vertebrae lumbalis

2. Discus intervertebrae lumbalis

3. Spinal cord

4. Cerebro spinal fluid (CSF)

Gambar 1. merupakan citra corpus, diskus, spinal cord, cerebro spinal fluid (CSF) pada pemeriksaan MRI lumbal sekuen T1WI TSE potongan sagital dengan pemakaian penggunaan SENSE (a) dan tanpa penggunaan SENSE (b) pada kasus Hernia Nucleus Pulposus (HNP).

2. Perbedaan kualitas citra (SNR) MRI lumbal sekuen T1WI TSE potongan sagital dengan dan tanpa penggunaan SENSE pada kasus Hernia Nucleus Pulposus (HNP)

Penilaian kualitas citra dilakukan dengan cara mengukur nilai SNR Signal to Noise Ratio (SNR) dengan pengaturan Region of interest (ROI) pasa citra organ dan background citra. Ukuran ROI yang diberikan pada organ dan background citra sebesar 21,66 $\mathrm{mm}^{2}$. Background citra diletakkan pada sisi kanan tengah. Besarnya nilai sinyal yang diperolah citra organ dan nilai standar deviasi dari background citra seperti pada gambar 2 .

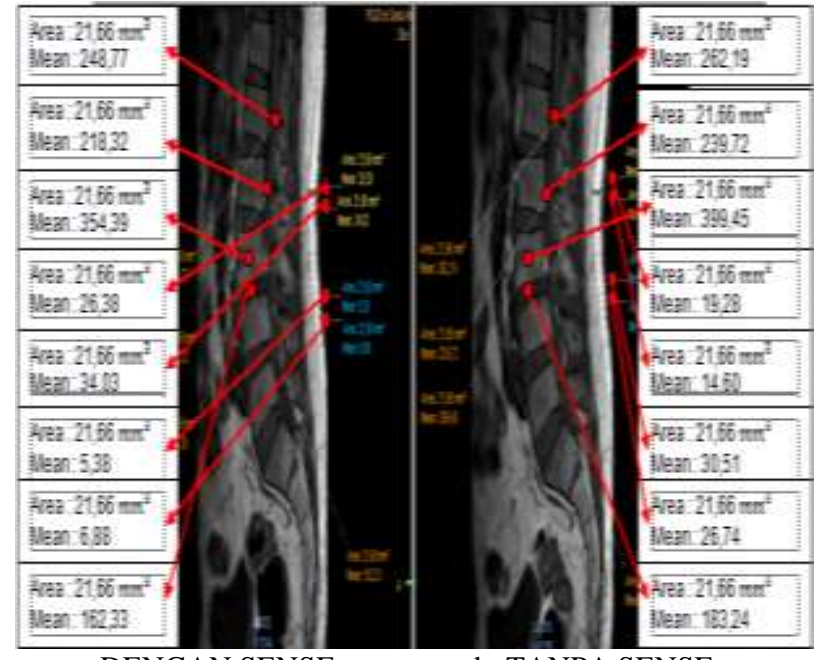

a. DENGAN SENSE

b. TANPA SENSE

Gambar 2. Hasil pengukuran ROI citra MRI lumbal kasus HNP antara menggunakan SENSE dan tanpa menggunakan SENSE

Hasil pengukuran nilai SNR pemeriksaan MRI lumbal sekuen T1WI TSE potongan sagital dengan penggunaan SENSE dan tanpa penggunaan SENSE pada kasus HNP seperti pada tabel 3 .

Tabel 3. Hasil Pengukuran SNR pemeriksaan MRI lumbal sekuen T1WI TSE potongan sagital dengan dan tanpa penggunaan SENSE pada kasus HNP

\begin{tabular}{ccc}
\hline Sampel & Dengan SENSE & Tanpa SENSE \\
\hline 1 & 101,30 & 90,73 \\
2 & 141,30 & 83,33 \\
3 & 114,20 & 89,26 \\
4 & 107,30 & 84,34 \\
5 & 109,40 & 92,87 \\
6 & 141,30 & 82,26 \\
7 & 118,30 & 84,29 \\
8 & 105,70 & 88,75 \\
9 & 127,10 & 91,43 \\
\hline Rata- & 141,30 & 92,87 \\
rata & & \\
\hline
\end{tabular}

Hasil Uji beda SNR pemeriksaan MRI Lumbal sekuen T1WI TSE potongan sagital dengan dan tanpa penggunaan SENSE pada kasus Hernia Nucleus Pulposus secara keseluruhan seperti ditampilkan pada tabel 4. 
Tabel 4. Hasil Uji beda nilai SNR antara penggunaan SENSE dan tanpa pengnggunaan SENSE

\begin{tabular}{lc}
\hline \multicolumn{1}{c}{ Variabel } & p-value \\
\hline & \\
Nilai SNR dengan SENSE - & 0,001 \\
Nilai SNR tanpa SENSE & \\
\hline
\end{tabular}

Tabel 4 menunjukkan bahwa secara keseluruhan ada perbedaan kualitas citra (SNR) pemeriksaan MRI lumbal sekuen T1WI TSE potongan sagital antara dengan penggunaan SENSE dan tanpa penggunaan SENSE pada kasus Hernia Nucleus Pulposus (HNP) dengan nilai signifikansi $\mathrm{p}$ value $=0,001(\mathrm{p}<0,05)$.

Berdasarkan hasil uji beda, nilai SNR MRI lumbal sekuen T1WI TSE potongan sagital dengan dan tanpa penggunaan SENSE pada kasus Hernia Nucleus Pulposus (HNP) menunjukkan bahwa ada perbedaan nilai SNR yang signifikan dengan dan tanpa penggunaan SENSE yaitu 0,001 .

Penggunaan teknik SENSE khususnya pasien dengan keluhan nyeri saat berbaring membutuhkan waktu pemeriksaan yang cepat, hal tersebut karena waktu akuisisi menjadi berkurang pada teknik SENSE sehingga meminimalisir terjadinya artefak yang disebabkan pergerakan Cerebro Spinal Fluid (CSF) (Forshult, 2007; Yasuyuki, 2002).

3. Perbedaan informasi anatomi MRI lumbal sekuen T1WI TSE potongan sagital dengan dan tanpa penggunaan SENSE pada kasus Hernia Nucleus Pulposus (HNP)

Hasil ppenilain informasi anatomi pemeriksaan MRI lumbal sekuen T1WI TSE potongan sagital antara dengan penggunaan SENSE dan tanpa penggunaan SENSE Pada Kasus Hernia Nucleus Pulposus (HNP).

a. Uji Keselarasan penilaian Responden

Hasil penilaian kejelasan informasi anatomi dari kedua responden dilakukan analisis dengan menggunakan uji Cohen"s Kappa untuk mengetahui tingkat keselarasan /kesepahaman penilaian antara kedua responden untuk mengetahui obyektifitas penilaian. Hasil uji Cohen"s Kappa seperti pada tabel 5 .
Tabel 5. Hasil uji keselarasan antar responden

\begin{tabular}{lc}
$\begin{array}{c}\text { Kejelasan Informasi Anatomi } \\
\text { hasil penilaian dua responden }\end{array}$ & $\begin{array}{c}\text { Koeff } \\
\text { Kappa }\end{array}$ \\
\hline Dengan SENSE & 0,711 \\
& \\
Tanpa SENSE & 0,741 \\
\hline
\end{tabular}

Uji Kappa dengan menggunakan SENSE antara dua responden sebesar 0,711 sedangkam tanpa menggunakan SENSE sebesar 0,741. Hasil uji menunjukkan bahwa kedua responden memiliki realibilitas baik dalam menilai kejelasan informasi anatomi MRI lumbal sekuen T1WI TSE potongan sagital dengan dan tanpa penggunaan SENSE pada kasus Hernia Nucleus Pulposus (HNP).

b. Uji beda informasi anatomi secara keseluruhan MRI lumbal sekuen T1WI TSE potongan sagital dengan dan tanpa penggunaan SENSE pada kasus Hernia Nucleus Pulposus (HNP)

Hasil uji Beda terhadap informasi anatomi MRI lumbal sekuen T1WI TSE potongan sagital dengan dan tanpa penggunaan SENSE pada kasus Hernia Nucleus Pulposus (HNP) secara keseluruhan seperti pada tabel 6 .

Tabel 6. Hasil uji beda informasi anatomi secara keseluruhan MRI lumbal sekuen T1WI TSE potongan sagital dengan dan tanpa penggunaan SENSE pada kasus (HNP)

\begin{tabular}{lc}
\hline Variabel & p-value \\
\hline Informasi Anatomi dengan SENSE - & \\
Informasi Anatomi tanpa SENSE & $<0,001$
\end{tabular}

Hasil Uji Beda menunjukkan bahwa ada perbedaan pada informasi anatomi citra secara keseluruhan MRI lumbal sekuen T1WI potongan sagital dengan dan tanpa penggunaan SENSE pada kasus Hernia Nucleus Pulposus (HNP) pada tingkat kepercayaan (level of confidence) $95 \% \mathrm{p}$ value $<0,001(\mathrm{p}<0,05)$.

Untuk mengetahui secara lebih detail perbedaan setiap anatomi dalam MRI lumbal pada kasus HNP dilakukan uji beda dengan Wilcoxon test dengan hasil seperti pada tabel 7. 
Tabel 7. Uji beda informasi anatomi setiap bagian MRI Lumbal pada kasus HNP antara penggunaan SENSE dan Tanpa penggunaan SENSE

\begin{tabular}{lc}
\hline \multicolumn{1}{c}{ Variabel } & p-value \\
\hline $\begin{array}{l}\text { Korpus dengan SENSE - } \\
\text { Korpus tanpa SENSE }\end{array}$ & 0,008 \\
\hline $\begin{array}{l}\text { Diskus dengan SENSE - } \\
\text { Diskus tanpa SENSE }\end{array}$ & 0,021 \\
\hline $\begin{array}{l}\text { Spinal cord dengan SENSE - } \\
\text { Spinal Cord tanpa SENSE }\end{array}$ & 0,011 \\
\hline CSF dengan SENSE - & \\
CSF tanpa SENSE & 0,139 \\
\hline
\end{tabular}

Hasil uji beda setiap antomi pada MRI lumbal menunjukkan terdapat perbedaan kejelasan gambaran Korpus vertebrae antara penggunaan SENSE dengan tanpa menggunakan SENSE dengan $p$ value $=0,008(p<0,05)$, terdapat perbedaan kejelasan gambaran Diskus intervertebrae antara penggunaan SENSE dengan tanpa menggunakan SENSE dengan $p$ value $=0,011(\mathrm{p}<0,05)$, terdapat perbedaan kejelasan gambaran Spinal kord antara penggunaan SENSE dengan tanpa menggunakan SENSE dengan $\mathrm{p}$ value $=0,021$ ( $\mathrm{p}<0,05)$. Hasil Uji beda setiap komponen anatomi menunjukkan tidak terdapat perbedaan kejelasan gambaran Cerebro Spinal Fluid antara penggunaan SENSE dan tanpa menggunakan SENSE dengan $p$ value $=0,139$ $(\mathrm{p}>0,05)$.

Hasil uji beda menunjukkan bahwa ada perbedaan informasi anatomi MRI lumbal sekuen T1WI TSE potongan sagital dengan dan tanpa penggunaan SENSE pada kasus Hernia Nucleus Pulposus (HNP) dengan pvalue $<0,001$.

Pada SENSE, koil phase array mengukur dan memproses sinyal dari sebuah potongan, kemudian menggabungkan potongan untuk membentuk citra yang meliputi area anatomi yang lebih besar. Waktu scan menjadi berkurang karena berkurangnya jumlah baris yang diperoleh untuk setiap elemen koil (Elster, 2015; Notoadmojo, 2002). Jumlah elemen koil yang digunakan dalam pengukuran adalah proporsional unutk pengurangan waktu scan. Dengan adanya waktu scan yang lebih cepat dapat megurangi dan mencegah terjadinya image blurring atau artefak yang diakibatkan karena pergerakan Cerebro Spinal Fluid (CSF) (Elster, 2015; Notoadmojo, 2002).

Teknik yang cepat memiliki keuntungan tidak hanya dari mengurangi artefak dari pergerakan tetapi juga potensial untuk mengurangi waktu akuisisi. Teknik SENSE memiliki potensial tersebut yaitu dengan menggunakan sekuen yang cepat dengan penggunaan gradien yang dioptimalkan, sehingga potensial untuk mendapatkan pengurangan waktu akuisisi tanpa mengurangi efek artefak yang signifikan pada citra yang diperoleh (Dale, 2015).

4. Kualitas citra (SNR) yang lebih baik pada MRI lumbal sekuen T1WI TSE potongan sagital antara menggunakan SENSE dan tanpa menggunakan SENSE pada kasus HNP

Untuk mengetahui yang menghasilkan kualitas citra dilihat dari hasil paired T test. Nilai rata rata SNR MRI lumbal sekuen T1WI TSE potongan sagital dengan dan tanpa penggunaan SENSE pada kasus Hernia Nucleus Pulposus seperti pada tabel 8 .

Tabel 8. Nilai mean pada penilaian kualitas citra MRI lumbal sekuen T1WI TSE potongan sagital dengan dan tanpa penggunaan SENSE

\begin{tabular}{lc} 
a & $\begin{array}{c}\text { Rata Rata } \\
\text { SNR }\end{array}$ \\
\hline Nilai SNR dengan penggunaan & 118,433 \\
SENSE & \\
Nilai SNR tanpa penggunaan & 87,473 \\
SENSE &
\end{tabular}

Tabel 8 menunjukkan bahwa dari hasil uji beda pemeriksaan MRI lumbal dengan penggunaan SENSE menghasilkan kualitas citra (SNR) lebih baik dengan nilai nilai Rata Rata SNR lebih 118,4333 sedangkan tanpa menggunakan SENSE nilai rata rata SNR sebesar 87,4733.

Nilai mean dari uji paired $T$ test kualitas citra, menunjukkan nilai tersebut lebih baik dibandingkan dengan nilai mean yang rendah. Adapun nilai mean MRI lumbal sekuen T1WI TSE potongan sagital dengan dan tanpa penggunaan SENSE pada kasus Hernia Nucleus Pulposus (HNP) menunjukkan bahwa dengan menggunakan SENSE nilai mean lebih tinggi yaitu 118,4333 tanpa menggunakan SENSE yaitu 87,4733 .

5. Informasi anatomi yang lebih baik MRI lumbal sekuen T1WI TSE potongan sagital dengan dan tanpa penggunaan SENSE pada kasus Hernia Nucleus Pulposus

Untuk mengetahui yang menghasilkan informasi anatomi yang lebih baik MRI lumbal 
sekuen T1WI TSE potongan sagital dengan dan tanpa penggunaan SENSE pada kasus Hernia Nucleus Pulposus (HNP), maka dilakukan uji Wilcoxon. Nilai peringkat (mean rank) MRI lumbal sekuen T1WI TSE potongan sagital dengan dan tanpa penggunaan SENSE pada kasus Hernia Nucleus Pulposus seperti disajikan pada tabel 9.

Tabel 9. Peringkat terbaik menampilkan Informasi anatomi MRI lumbal sekuen T1WI TSE potongan sagital dengan dan tanpa penggunaan SENSE pada kasus HNP

\begin{tabular}{lc}
\hline \multicolumn{1}{c}{ Variabel } & Mean Rank \\
\hline Informasi Anatomi dengan & 11,00 \\
SENSE & \\
Informasi Anatomi Tanpa & 6,00 \\
SENSE & \\
\hline
\end{tabular}

Dengan menggunakan SENSE akan menghasilkan gambaran informasi anatomi MRI Lumbal pada kasus HNP yang lebih baik dibandingkan tanpa penggunaan SENSE dengan nilai mean rank 11,00 .

Peringkat terbaik yang mampu menampilkan informasi setiap bagian anatomi MRI lumbal sekuen T1WI TSE potongan sagital dengan dan tanpa penggunaan SENSE pada kasus Hernia Nucleus Pulposus seperti pada tabel 10.

Tabel 10. Peringkat terbaik menampilkan informasi setiap bagian anatomi MRI lumbal sekuen T1WI TSE potongan sagital dengan dan tanpa penggunaan SENSE pada kasus HNP

\begin{tabular}{lc}
\hline \multicolumn{1}{c}{ Variabel } & Mean Rank \\
\hline Korpus dengan SENSE - & 45 \\
Korpus tanpa SENSE & 0 \\
\hline Diskus dengan SENSE - & 42 \\
Diskus tanpa SENSE & 3 \\
\hline Spinal cord dengan SENSE - & 44 \\
Spinal Cord tanpa SENSE & 1 \\
\hline CSF dengan SENSE - & 35 \\
CSF tanpa SENSE & 10
\end{tabular}

Nilai mean rank pada uji Wilcoxon informasi anatomi, MRI lumbal sekuen T1WI TSE potongan sagital dengan dan tanpa penggunaan SENSE pada kasus Hernia Nucleus Pulposus. menunjukkan bahwa dengan menggunakan SENSE nilai mean rank lebih tinggi yaitu 11,00 sedangkan tanpa menggunakan SENSE yaitu 6,00 .

Nilai SNR akan terjadi perubahan jika mengaktifkan penggunaan SENSE. Nilai SNR akan mengalami penurunan karena rekonstruksi SENSE dapat membangkitkan semua coil yang bekerja sehingga pengambilan gambar dapat bekerja dengan cepat dan dengan hal tersebut scan time menjadi lebih singkat, sehingga dapat menurunkan resolusi SNR menjadi lebih rendah, dan kualitas citra menjadi turun (Mueller, 2003; Elmouglu, 2012).

Waktu akuisisi data yang dihasilkan dengan menggunakan SENSE yaitu 3 menit sedangkan tanpa menggunakan SENSE 4 menit. Waktu scan menjadi berkurang karena berkurangnya jumlah baris yang diperoleh untuk setiap elemen. Jumlah elemen yang digunakan dalam pengukuran adalah proporsional untuk pengurangan waktu scan (Dale, 2015; Morelli, 2011).

Pada penilaian informasi anatomi pada MRI lumbal sekuen T1WI TSE potongan sagital dengan dan tanpa penggunaan SENSE pada kasus Hernia Nucleus Pulposus (HNP) bahwa dengan menggunakan SENSE lebih baik dibandingkan tanpa menggunakan SENSE (Moeller, 2003).

Dengan menggunakan atau pengaktifan SENSE yang cepat memiliki keuntungan tidak hanya dari mengurangi artefak dari pergerakan tetapi juga potensial untuk mengurangi waktu akuisisi (Elster, 2015; Westbrook, 2014).

\section{Kesimpulan}

Berdasarkan hasil penelitian dapat disimpulkan bahwa :

1. Terdapat perbedaan kualitas citra (SNR) antara penggunaan SENSE dan tanpa penggunaan SENSE pemeriksaan MRI lumbal sekuen T1WI potongan sagital dengan $\mathrm{p}$-value $<0,001$

2. Terdapat perbedaan informasi Anatomi antara penggunaan SENSE dan tanpa penggunaan SENSE pemeriksaan MRI lumbal sekuen T1WI potongan sagital dengan $\mathrm{p}$-value $=0,001$

3. Penggunaan SENSE mampu menghasilkan kualitas Citra MRI (SNR) dan Informasi Anatomi MRI lumbal sekuen T1WI potongan sagital.

Terimakasih peneliti sampaikan kepada Direktur Poltekkes Kemenkes Semarang atas pemberian dana untuk penelitian ini. Terimakasih juga peneliti sampaikan kepada RS dr Saiful Annwar khususnya bagian radiologi atas ijin dan bantuan dalam pelaksanaan penelitian. 


\section{Daftar Pustaka}

Dale, M. Brian, M.A Brown dan Richard C. Semelka, 2015, MRI Basic Principle and Applications, Fifth Edition, New Jersey : John Wiley and Sons Inc.

Deshmane, Anagha., Gulani, Vikas., Griswold, Mark A., Seiberlich, Nicole, 2012. Parallel MR Imaging. HHS Public Access.

Elmaouglu, Muhammed. Celik, Azim. 2012. MRI Handbook MR Physics, Patient Positioning, and Protocols. New York: Springer.

Elster, AD, 2015, Explain how does SENSE / ASSET work, Elster LLC, mri-q.com

Filippi Christopher G., Carlson Morgan., Johnson Jason M., Heather N. Burbank., Alsofrom F Gary., Andrews Trevor. 2012. Improvements in Lumbar Spine MRI at 3 T Using Parallel Transmission. AJR

Fitriyani, et al. 2017. System Pakar Diagnosis Penyakit Hernia Nucleus Pulposus Menggunakan Forward Chainning Berbasis Web, Volume 17 Nomor 3.

Forshult, Stig E, 2007, magnetic resonance imaging- MRI- An Overview, Karlstad university, Swedia.

Glockner, James F, MD, PhD, Houchun $\mathrm{H}$. Hu, BME, David W. Stanley, BS, Lisa Angelos, $\mathrm{PhD}$ dan Kevin King, PhD, 2005. Paralel Imaging : A User Guide. RSNA.

Moeller, Torsten B. Reif, Emil. 2003. MRI Parameters and Positioning. New York: Thieme.

Moeller, TB. Dan Reif, E. 2007. Pocket Atlas of Sectional Anatomy Computed Tomography and Magnetic Resonance Imaging. Volume III: Spine, Extremities, Joints. New York : Thieme Stuttgart.

Morelli, John N, Val M. Runge, Fei Ai, Ulrike Attenberger, Lan Vu, Stuart H. Schmeets, Wolfgang R. Nitzdan John E. Kirsch, 2011, An Image-Based Approach to Understanding the Physics of MR Artifacts, radiographics.rsna.org.

Notoatmodjo S. 2002, Metodologi Penelitian Kesehatan, Jakarta ; Rineka Cipta.
Westbrook, Catherine, 2014. Handbook of MRI Technique 4th Edition, United Kingdom : Blackwell Science Ltd.

Yasuyuki, Kurihara., Yakushiji, K.Y., Tani, Ichiro., Nakajima, Yasuo., danCauteren, V.M., 2002. Coil Sensitivity Encoding : Advantage and Disadvantage, in Clinical Practice. American Roentgen Ray Society. 